\title{
Idiosyncratic and normative mediators in paired associate learning ${ }^{1}$
}

\author{
C. MICHAEL LEVY AND DOROTHY NEVILL
} UNIVERSITY OF FLORIDA

In a further investigation of the Russell-Storms paradigm, Ss were permitted to form chained associations on the basis of their own or of other Ss' idiosyncratic associative hierarchies or of free association norms. When lists were tailored to $S$ 's own associative hierarchy the magnitude of the assumed mediation was no greater than when they were constructed from norms based upon a different sample of $S$ s.

In their classic study, Russell \& Storms (1955) reported second list facilitation in learning $A-B, A-D$ paired associates when an extra-experimentally established $B \rightarrow C \rightarrow D$ chain could be assumed as a mediational link. Their lists, constructed from the Minnesota norms, had rather low $B \rightarrow C$ and $C \rightarrow D$ associative strengths, varying between .14 and .40. Perhaps as a consequence, the magnitude of the mediational effect, while significant, was small. Since mediation is such an important concept for certain current S-R theories, it was felt that Russell and Storms' procedures should be modifed to allow mediation to show better its empirical power.

One alteration would use $B \rightarrow C \rightarrow D$ chains with stronger associative bonds than those employed by Russell and Storms. In its extreme version, this modification would institute explicit C mediators. Martin \& Dean (1964) have shown that explicit mediators did indeed facilitate learning, but found that only a small number of words used as explicit mediational links corresponded to those of the word association norms.

Another alternative would require construction of a different test list for each $\mathrm{S}$ based upon his idiosyncratic associative hierarchies. This modification of the Russell-Storms study was used in the present experiment.

Method

Approximately one month prior to the experiment, the idiosyncratic free association responses were obtained from all Ss to the 10 nouns used by Russell and Storms and to 14 additional nouns. These words were printed on the first page of an NCR (no carbon required) booklet (see Bllodeau \& Fox, 1965). Four forms were prepared, differing only in the serial order of the 24 items. The $\mathrm{S}$ wrote beside each word his first free associate (C). After about $4 \mathrm{~min}$, when $\mathrm{S}$ had responded to all B words, he turned the page, found the $C$ words in his own handwriting, and wrote his first associate (D) to each. Similarly, on the following page, $\mathrm{S}$ associated to the $\mathrm{D}$ words, producing $\mathrm{E}$ words. Any $S$ repeating a response within the $B \rightarrow C \rightarrow D \rightarrow E$ chain was prohibited from serving in the Idiosyncratic group.
The Es used in the experiment were not present during this session.

Except for the differences among the three groups' second list, the procedural details of the experiment were identical to Russell and Storms'. Briefly, all Ss learned the same A-B list, where the A term was a CVC ( $0 \%$ association value) and B was one of the following nouns: stem, memory, soldier, trouble, wish, justice, thief, ocean, command, fruit. The pairs were presented on a memory drum at a 2:2 rate until $S$ had reached a criterion of three errorless trials. Following a $4 \mathrm{~min}$ rest, List 2 was administered.

List 2 for Group R-S contained the five A-D and five A-X pairs used by Russell and Storms. The D terms were normatively related to the $B$ terms through the chain, $B \rightarrow C \rightarrow D$. The $X$ terms were words unrelated to the $B$ and $C$ words.

The second list for the Idiosyncratic (I) group also contained five A-D and five A-X pairs, but the D terms originated in the list of free association responses previously obtained from each $\mathrm{S}$. The $\mathrm{X}$ items were identical to those in Group $R-S$. It should be clear that each $\mathrm{S}$ in Group I received a different List 2.

In order to ascertain if the pairs in List 2 were inherently easier for Group I than for Group R-S, an additional group was used. Each of the second lists prepared for Group I was presented to the Ss in this control (C) group. Thus each $\mathrm{S}$ in Group $\mathrm{C}$ mastered a List 2 which was also learned by an $S$ in Group I.

Two forms of List 2 were prepared for each group which differend in the five A items which were paired with $D$ and $X$ items. All Ss were trained at a 2:2 rate to a criterion of one errorless trial on List 2.

Seventy-two students serving a course requirement at the University of Florida participated in the experiment. Male and female Ss were equally divided among the 12 cells formed by the three groups, two forms, and two Es, but were otherwise unsystematically assigned.

\section{Results and Discussion}

The mean number of trials to criterion on List 1 for Groups $\mathrm{R}-\mathrm{S}, \mathrm{I}$, and $\mathrm{C}$ was $22.0,22.5$, and 25.5, respectively. For List 2 the corresponding means were 11.1, 11.5, and 13.3. These values were very close to those reported by Russell and Storms. Although List 2 was learned faster than List 1 ( $F=154.27$, $\mathrm{df}=1 / 48, \mathrm{MS}_{\mathrm{e}}=29.17$ ), there were no differences among the three groups in reaching either criterion (Groups' $F=1.47, \mathrm{df}=2 / 48, \mathrm{MS}_{\mathrm{e}}=92.93$; Groups by Lists' $F=$ 0.08 , $d f=2 / 48$ ). Thus, the independent variable was 


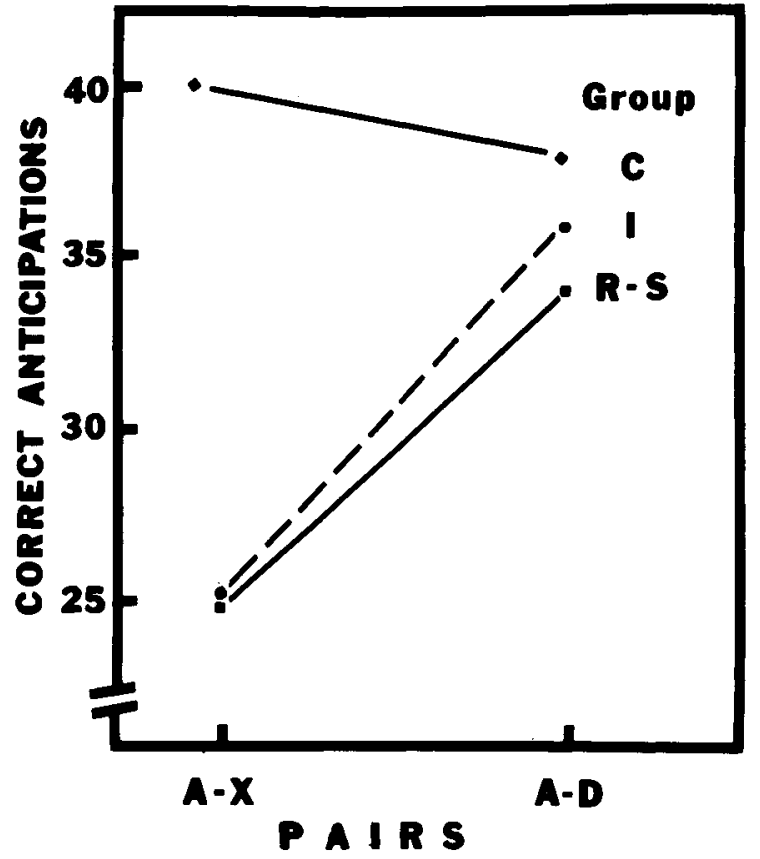

Fig. 1. Mean number of correct anticipations to the chained (A-D) and unchained (A-X) pairs during List 2 learning.

not powerful enough to produce differential difficulty as measured by trials to criterion.

The groups could be distinguished, however, by their response patterns to chained $(B \rightarrow C \rightarrow D)$ and unchained pairs. Fifty-nine percent of the correct anticipations made by Group I during List 2 learning were made to the chained pairs. The corresponding figures for Groups R-S and C were 57.7 and 49.3 , respectively. The mean number of correct anticipations per $S$ for the two categories are shown in Fig. 1. More correct anticipations were given to the chained pairs $\left(F=14.37, \mathrm{df}=1 / 32, \mathrm{MS}_{\mathrm{e}}=1.59\right)$, but this pattern was clearly reversed in Group $C$, producing a significant Groups by Chained-Unchained interaction $(F=5.28, d f=2 / 32)$. A Newman-Keuls test revealed that Groups $\mathrm{R}-\mathrm{S}$ and I differed neither in terms of the number of correct anticipations to the chained nor to the unchained pairs. All other possible comparisons among the six means shown in Fig. 1 were statistically significant at the 0.01 level.

It would appear that the generality of Russell and Storms' widely cited findings need not be restricted due to their use of norms reflecting relatively weak associative strength among items in the chain. When lists were tailored to an individual's own associative hierarchy, the magnitude of the assumed mediation was no greater than when lists were constructed from norms based upon a different sample of Ss. Only when another individual's associative hierarchy was employed (i.e., Group C) did Ss encounter difficulties in learning the second list.

Since Fox (1965) found a high degree of consistency among Ss' responses over time in a word association task, it is unlikely that the strength of S's association between $\mathrm{B}$ and $\mathrm{C}$ and between $\mathrm{C}$ and $\mathrm{D}$ were substantially reduced during the period between the gathering of the idiosyncratic responses and the experiment. Rather, the results substantiate Jenkins' (in press) findings that only the relative strength of pairings was related to rate of acquisition.

\section{References}

BILODEAU, E. A., \& FOX, P. W. The NCR booklet: A group technique for studying word arousal phenomenon as a function of S's idiosyncratic habits. Psychon. Sci., 1965, 2, 223-224.

FOX, P. W. Word association reliability. Paper presented at Psychonomic Society meetings, Chicago, October, 1965.

JENKINS, J. J. The 1952 word association norms. In L. Postman (Ed.), Norms of word association. New York: Academic Press, in press.

MARTIN, R. B., \& DEAN, S. J. Implicit and explicit mediation in pairedassociate learning. J. exp. Psychol, 1964, 68, 21-27.

RUSSELL, W. A., \& STORMS, L. H. Implicit verbal chaining in pairedassociate learning. J. exp. Psychol, 1955, 49, 287-293.

Note

1. The authors acknowledge the very competent assistance of Mr. Patrick $\mathrm{H}$. Murphy, III given to the data collection. Manuscript preparation was facilitated by a research leave granted to the senior author by the Institute of Social Sciences, University of Florida. 